\title{
INFLUÊNCIA DA LIOFILIZAÇÃO SOBRE OS CAROTENOIDES DE FRUTOS DO CERRADO E COMPORTAMENTO HIGRÓSCOPICO DOS PRODUTOS LIOFILIZADOS
}

\author{
Erika Lopes Duarte \\ Engenheira de Alimentos - Universidade Federal de \\ São João del-Rei - Campus Sete Lagoas/ MG \\ erikal.duarte@ hotmail.com
}

\author{
Lanamar de Almeida Carlos \\ Doutora em Produção Vegetal - Universidade \\ Federal de São João del-Rei - Campus Sete Lagoas/ \\ MG \\ lanamar@ufsj.edu.br
}

\section{Camila Gonçalves Rodrigues}

Engenheira de Alimentos - Universidade Federal de São João del-Rei - Campus Sete Lagoas/ MG

kkgoncalves_ufsj@yahoo.com.br

\author{
Roberta Manoel Andrade \\ Graduanda em Engenharia de Alimentos - \\ Universidade Federal de São João del-Rei - \\ Campus Sete Lagoas/ MG \\ roberta-manoel@hotmail.com
}

\section{Kênia Grasielle de Oliveira}

Mestre em Ciências Agrárias - Universidade Federal de São João del-Rei - Campus Sete Lagoas/ MG

keniagrasi@yahoo.com.br

\section{RESUMO}

O marolo e cagaita são frutos do Cerrado que possuem excelentes características nutricionais, mas são altamente perecíveis e não estão disponíveis em períodos de entressafra. A liofilização é um processo de secagem que oferece produtos de elevada qualidade. Sendo assim, objetivou-se obter o pó comestível a partir das polpas de marolo e cagaita liofilizadas, avaliar o efeito do processo de secagem sobre a preservação do conteúdo de carotenoides e sobre o comportamento higroscópico dos correspondentes produtos liofilizados. Foram avaliados os parâmetros físico-químicos e o conteúdo de carotenoides totais da polpa in natura e liofilizada. Os produtos liofilizados foram avaliados quanto à atividade de água, molhabilidade, solubilidade, capacidade de reidratação e comportamento higroscópico. Os correspondentes pós provenientes da liofilização de marolo e de cagaita apresentaram alta solubilidade e molhabilidade. As isotermas de adsorção dos pós de ambos os frutos liofilizados apresentaram comportamento típico de materiais com alto teor de açúcares. Os parâmetros físico-químicos não foram influenciados pelo processo de liofilização, contudo, observou-se uma perda de aproximadamente $40 \%$ de carotenoides totais para a cagaita liofilizada em relação à polpa in natura. É viável a produção de pós comestíveis de marolo e de cagaita, contudo são necessários mais estudos visando minimizar a higroscopicidade desses produtos a partir de frutas liofilizadas.

Palavras-chave: Annona crassiflora; Eugenia dysenterica; Preservação de alimentos.

Persp. online: biol. \& saúde, Campos dos Goytacazes, 23 (7), 22 - 33, 2017

seer.perspectivasonline.com.br 


\begin{abstract}
Marolo and cagaita are fruits of the Cerrado that have excellent nutritional characteristics, but are highly perishable and are not available in off-season. Lyophilization is a drying process that offers high quality products. The objective of this study was to obtain the edible powder from lyophilized marolo and cagaita pulps, to evaluate the effect of the drying process on the preservation of the carotenoid content and on the hygroscopic behavior of the corresponding lyophilized products. The physical-chemical parameters and the total carotenoid content of the in natura and lyophilized pulp were evaluated. The lyophilized products were evaluated for water activity, wettability, solubility, rehydration capacity and hygroscopic behavior. The corresponding powders obtained from lyophilization of marolo and cagaita showed high solubility and wettability. The adsorption isotherms of the powders of both lyophilized fruits presented typical behavior of materials with high sugar content. The physicochemical parameters were not influenced by the lyophilization process, however, a loss of approximately $40 \%$ of total carotenoids was observed for lyophilized cagaite in relation to the in natura pulp. It is feasible the production of edible powders of marolo and cagaita, however further studies are needed to minimize the hygroscopicity of these products from lyophilized fruits.
\end{abstract}

Keywords: Annonacrassiflora; Eugenia dysenterica; Food preservation.

\title{
1. INTRODUÇÃO
}

O Bioma Cerrado ocupa uma área expressiva do território brasileiro, onde é possível observar grande variabilidade de clima, de solos e, por conseguinte, grande diversidade de fauna e flora (VERA et al, 2005). Contudo, este importante Bioma vem sendo rapidamente devastado para criação de novas áreas de pastagens ou plantio de oleaginosas, como soja (ROESLER et al., 2007; ROCHA, 2011).

A busca de novas alternativas de alimentos, a exploração sustentável do Bioma Cerrado, bem como o conhecimento acerca de frutos consumidos por populações regionais, aliados à importância do consumo de frutas como fontes naturais de compostos bioativos, atualmente veiculadas maciçamente pela mídia, são fatores que na última década tem alavancado a pesquisa tanto em âmbito nacional como internacional.

O Cerrado apresenta diversas espécies frutíferas com alto potencial de utilização agrícola. Geralmente, a população local utiliza os frutos para consumo in natura ou processadas na forma de licores, sucos, geleias e doces. Hoje, cerca de 58 espécies de frutas nativas conhecidas dos cerrados são utilizadas pela população da região e outros estados (ROCHA, 2011). De um modo geral, a sazonalidade é um fator que limita a comercialização e o acesso de populações a esses frutos.

Os frutos nativos do Cerrado têm despertado interesse devido as suas propriedades funcionais e nutricionais, aliadas à presença de compostos bioativos, que podem apresentar efeitos fisiológicos adicionais mesmo em pequenas quantidades. Apesar do seu importante valor nutritivo, esses frutos apresentam pouco ou nenhum valor comercial.

Dentre as espécies frutíferas que caracterizam o Cerrado estão o araticunzeiro (Annona crassiflora Mart.) e a cagaitera (Eugenia dysenterica DC). Seus frutos podem apresentar valores equivalentes ou superiores de vitaminas do complexo B aos encontrados em frutas tradicionalmente consideradas como boa fonte dessas vitaminas como a goiaba, banana e abacate. $\mathrm{O}$ araticum, também conhecido como marolo ou cabeça de nego e a cagaita são populares no Centro-Oeste brasileiro e praticamente desconhecidos no restante do país (VERA et al., 2005; PINEDO et al., 2013).

Persp. online: biol. \& saúde, Campos dos Goytacazes, 23 (7), 22 - 33, 2017

seer.perspectivasonline.com.br 
Devido à alta perecibilidade e a indisponibilidade destes frutos durante o período de entressafra, é gerada uma demanda de conhecimento acerca de processos que permitam o prolongamento da vida de prateleira dessas matérias-primas, de maneira a conservar suas características originais. A desidratação é uma excelente alternativa para suprir esta demanda e garantir o comércio e estocagem do fruto em períodos de entressafra.

A liofilização (freeze-drying) é conhecida como o processo de secagem que oferece produtos de elevada qualidade. A ausência de água líquida e as baixas temperaturas envolvidas no processo minimizam a migração de sólidos solúveis no interior do material, inibe reações de alterações químicas, favorecendo a retenção de componentes aromáticos voláteis, bem como a estrutura porosa do material seco que facilita sua rápida reidratação (KING, 1988; RATTI, 2001).

Este trabalho teve como objetivo a obtenção de pó comestível a partir das polpas de marolo e cagaita liofilizadas e avaliação do efeito desse processo sobre a preservação do conteúdo de carotenoides e o comportamento higroscópico dos correspondentes liofilizados.

\section{MATERIAIS E MÉTODOS}

2.1 Obtenção e preparo dos frutos: Os frutos foram adquiridos diretamente de comerciantes extrativistas da região de Sete Lagoas-MG, conforme a época de frutificação. O marolo (A. crassiflora) foi proveniente de São José da Lagoa/MG e a cagaita (E. dysenterica) de Sete Lagoas/MG no Campus da Universidade Federal de São João del Rei (UFSJ/CSL). Para o processamento foram utilizados aqueles que se encontraram morfologicamente perfeitos, no estádio de maturação considerado como apropriado para o consumo in natura (casca na coloração amarela para a cagaita e o marolo com a casca amarronzada). Os frutos foram transportados sob refrigeração até o Laboratório de Ciência e Tecnologia de Alimentos II da UFSJ-CSL, onde foram lavados e sanitizados em água clorada (150 ppm de cloro ativo). A separação das cascas e sementes foi realizada manualmente. Em seguida o material foi submetido ao congelamento por ar estático à $-80^{\circ} \mathrm{C}$ em ultrafreezer (COLDLAB modelo CL880), onde permaneceu por 48 horas e posteriormente submetido à liofilização em Liofilizador (JJ Científica modelo JJ 06).

2.2 Delineamento experimental: O experimento foi conduzido de acordo com o delineamento inteiramente casualizado com três repetições. Todos os resultados foram analisados por meio da análise de variância (ANOVA) com auxílio do modelo computacional SISVAR (FERREIRA, 2003), e as médias submetidas ao teste de Tukey com erro de $5 \%$ de probabilidade.

\subsection{Caracterização dos frutos (polpa) in natura:}

2.3.1 Determinação da Cor: A determinação da coloração da polpa de cada fruto foi efetuada com o auxílio de um colorímetro Konica Minolta, modelo CR 410, fazendo-se medidas em três pontos distintos na parte equatorial de cada fruto, após remoção da casca. Os resultados foram expressos na proporção dos parâmetros "L" (luminosidade), "a" e "b" (cromaticidade) e ângulo hue $\left(\mathrm{h}^{\circ}\right)$, conforme realizado por Silva et al. (2008).

2.3.2 Teor de sólidos solúveis totais: Os teores de sólidos solúveis totais foram determinados colocando-se gotas das polpas homogeneizadas e filtradas sobre o prisma de um refratômetro digital Reichert $\mathrm{r} 2$ MINI. Os resultados foram expressos em ${ }^{\circ}$ Brix.

Persp. online: biol. \& saúde, Campos dos Goytacazes, 23 (7), 22 - 33, 2017

seer.perspectivasonline.com.br 
2.3.3 Teor de matéria seca (sólidos totais): As percentagens de matéria seca foram obtidas com base nos pesos inicial e final do material mantido em estufa a vácuo a $70^{\circ} \mathrm{C}$ até peso constante, conforme protocolo da AOAC (2012).

2.3.4 pH: $\mathrm{O}$ pH foi determinado por potenciometria através da inserção do eletrodo do pHmetro (MS Tecnopon Instrumentação mPA210) na polpa do fruto homogeneizada (AOAC, 2012).

2.3.5 Acidez Titulável: Para determinar acidez titulável, 10,0 gramas das polpas in natura homogeneizadas foram diluídas com água destilada até um volume de $50 \mathrm{~mL}$ e titulados com $\mathrm{NaOH} 0,1 \mathrm{~N}$, utilizando-se fenolftaleína como indicador, conforme a metodologia descrita no AOAC (2012).

2.3.6 Frutose e sacarose: Os conteúdos de glicose e frutose foram determinados por HPLC em um Cromatógrafo SHIMADZU, com detector de índice de refração modelo RID 10A, utilizando-se coluna Rezex RCM Monosaccharide $\mathrm{Ca}^{+2}$, água como fase móvel, fluxo de $1 \mathrm{~mL} / \mathrm{min}$ e temperatura do forno $85^{\circ} \mathrm{C}$ (ISLA et al, 1998).

2.3.7 Carotenoides: O conteúdo de carotenoides totais foi determinado utilizando a metodologia proposta por Rodriguez-Amaya, (2001), em espectrofotômetro digital a $450 \mathrm{~nm}$ e os resultados expressos em $\mu \mathrm{g}$ carotenoides totais/100 g amostra fresca.

\subsection{Caracterização dos correspondentes pós liofilizados:}

2.4.1 Parâmetros físico-químicos: A caracterização dos frutos após serem liofilizados foi realizada através das análises de cor, teor de matéria seca, sólidos solúveis totais, acidez titulável, pH e carotenoides de acordo com as metodologias descritas para a caracterização dos frutos in natura, modificando-se apenas na quantidade de amostra.

2.4.2 Atividade de água: Foi realizada com o auxílio do equipamento Aqualabite (Decagon Devices Inc., Pullman, WA, EUA).

2.4.3 Solubilidade: A determinação de solubilidade foi realizada segundo a metodologia proposta por Cano-Chauca et al., (2005), onde $1 \mathrm{~g}$ do pó foi adicionado a $100 \mathrm{~mL}$ de água destilada seguindo homogeneização e centrifugação a $2600 \mathrm{rpm}$ por $5 \mathrm{~min}$. Uma alíquota de $25 \mathrm{~mL}$ de sobrenadante foi transferida para uma placa de petri previamente pesada e submetida a secagem a $105^{\circ} \mathrm{C}$. A solubilidade foi calculada com base nas massas inicial da amostra $(1 \mathrm{~g})$ e a massa final após secagem de parte do sobrenadante.

2.4.4 Molhabilidade: $\mathrm{O}$ teste de molhabilidade foi baseado na metodologia proposta por Vissotto et al. (2006). O método se baseia na queda de $1,0 \mathrm{~g}$ de amostra sobre $100 \mathrm{~mL}$ de água deslilada a $25^{\circ} \mathrm{C}$, sem agitação e a medição do tempo (em segundos) necessário para que todas as partículas se molhem, sendo determinado visualmente.

2.4.5 Capacidade de reidratação: Foi realizada de acordo com a metodologia descrita pela USDA (2005), onde $5 \mathrm{~g}$ da amostra seca foi adicionada a $150 \mathrm{~mL}$ de água destilada em ebulição e mantida por mais 3 minutos sob fervura. Após este período a amostra reidratada foi então, transferida para um sistema de filtração a vácuo com funil de Büchner e papel de filtro. A água foi drenada da amostra com suave compressão. A amostra, foi pesada e a capacidade de reidratação calculada utilizando-se a equação COR= [mrh $(100-\mathrm{Xo})] /[\mathrm{mdh}(100-$ $\mathrm{Xdh})$ ], onde COR é o coeficiente de reidratação; mrh é a massa de amostra reidratada (kg); mdh é a massa de produto desidratado $(\mathrm{kg})$; Xo é o teor de umidade inicial e Xdh é o teor de umidade da amostra seca.

Persp. online: biol. \& saúde, Campos dos Goytacazes, 23 (7), 22 - 33, 2017

seer.perspectivasonline.com.br 
2.4.6 Determinação das características higroscópicas dos pós de frutos: Para avaliação do comportamento higroscópico, empregou-se o método gravimétrico estático com determinação do teor de umidade de equilíbrio (ANSARI et al., 2011; RANGEL-MARRÓN et al., 2011). As amostras foram previamente pesadas, acondicionadas em placas de petri e colocadas em dessecadores contendo solução saturada de cloreto de sódio para a obtenção de ambiente com 75\% de umidade relativa (ROCKLAND, 1960). Os dessecadores foram submetidos a vácuo parcial para favorecer a taxa de transferência de massa no processo de adsorção e foram mantidos em estufas tipo B.O.D sob temperatura de $20^{\circ} \mathrm{C}$. As placas contendo os pós foram pesadas em balança analítica a cada 24 horas até atingirem peso constante (por um período de 10 dias), conforme metodologia descrita por Carlos et al. (2005). As determinações foram feitas em triplicata e o teor de umidade adsorvida foi calculado com base na diferença de massa do estado inicial (antes de serem colocadas no dessecador) e final (após atingirem peso constante) das amostras.

\section{RESULTADOS E DISCUSSÃO}

\subsection{Caracterização físico-química}

As análises de cor dos frutos estão representadas na Tabela 1. O valor de $\mathrm{L}$ nos fornece a luminosidade, variando do branco $(\mathrm{L}=100)$ ao preto $(\mathrm{L}=0)$, a coordenada $\mathrm{a}^{*}$ pode assumir valores de $-80 \mathrm{a}+100$, em que os extremos correspondem ao verde e ao vermelho, respectivamente; e a coordenada $b^{*}$ corresponde à intensidade de azul ao amarelo, que pode variar de -50 (totalmente azul) a +70 (totalmente amarelo) (HARDER et al., 2007). Pode-se observar que a liofilização da polpa de marolo não influenciou significativamente nenhum dos parâmetros relacionados à caracterização da cor, enquanto a polpa de cagaita liofilizada apresentou aumento significativo $(\mathrm{p}<0,05)$ da luminosidade $\left(\mathrm{L}^{*}\right)$ e dos cromas $\mathrm{a}^{*}$ e $\mathrm{b}^{*}$ indicando acentuação da cor amarela.

Tabela 1. Cor instrumental dos frutos marolo e cagaita in natura e liofilizados expressa através dos parâmetros ângulo de Hue $\left(h^{\mathrm{o}}\right)$, luminosidade $(\mathrm{L})$, cromas a* e b*.

\begin{tabular}{ccccc}
\hline \multirow{2}{*}{ Parâmetros } & \multicolumn{2}{c}{ Marolo } & \multicolumn{2}{c}{ Cagaita } \\
\cline { 2 - 5 } & In natura & Liofilizado & In natura & Liofilizado \\
\hline $\mathbf{L}^{*}$ & $77,86^{\mathrm{a}}$ & $78,06^{\mathrm{a}}$ & $62,40^{\mathrm{a}}$ & $72,57^{\mathrm{b}}$ \\
$\mathbf{a}^{*}$ & $2,31^{\mathrm{a}}$ & $3,19^{\mathrm{a}}$ & $0,43^{\mathrm{a}}$ & $1,47^{\mathrm{b}}$ \\
$\mathbf{b}^{*}$ & $39,23^{\mathrm{a}}$ & $35,34^{\mathrm{a}}$ & $49,16^{\mathrm{a}}$ & $65,57^{\mathrm{b}}$ \\
$\boldsymbol{h}^{\circ}$ & $86,63^{\mathrm{a}}$ & $84,84^{\mathrm{a}}$ & $89,50^{\mathrm{a}}$ & $88,72^{\mathrm{a}}$ \\
\hline
\end{tabular}

*Médias seguidas por letras distintas nas linhas diferem entre si ao nivel de significancia de $5 \%$ pelo teste de Tukey $(\mathrm{p}<0,05)$.

O ângulo hue $\left(\mathrm{h}^{\circ}\right)$ é representado por um ângulo de $0^{\circ}$ a $360^{\circ}$ graus. Ângulos entre $0^{\circ}$ e $90^{\circ}$ são representados pelos vermelhos, laranjas e amarelos; de $90^{\circ}$ a $180^{\circ}$ são os amarelos, amarelo-verdes e verdes; $180^{\circ}$ a $270^{\circ}$ são os verdes, azul-verdes e azuis; de $270^{\circ}$ a $360^{\circ}$ são azuis, púrpuras, magentas e novamente os vermelhos (MARQUES, 2008). Nota-se que ambos os frutos in natura e em pó obtidos por liofilização estão próximos do ângulo de $90^{\circ}$, ou seja, próximos do ângulo que caracteriza a tonalidade amarela. Para ambos os frutos houve um decréscimo não significativo do valor do ângulo hue dos pós dos frutos liofilizados quando comparado com as polpas dos frutos in natura (Tabela 1).

Persp. online: biol. \& saúde, Campos dos Goytacazes, 23 (7), 22 - 33, 2017

seer.perspectivasonline.com.br 
De acordo com Bezerra (2014), a redução do ângulo hue $\left(\mathrm{h}^{\circ}\right)$ está associada à baixa temperatura e pressão de vácuo requeridas no processo de liofilização e possivelmente à degradação dos carotenoides presentes nos frutos. Os carotenoides são pigmentos responsáveis pela cor amarela e possuem estrutura química instável, sendo facilmente reativa.

Houve diminuição dos valores de $\mathrm{pH}$ e aumento da acidez titulável para a cagaita, enquanto o marolo mostrou-se menos ácido em relação a cagaita (Tabela 2). Os valores de $\mathrm{pH}$ encontrados para as frutas in natura foram inferiores aos citados por Martins (2006) relativos à frutos procedentes de Goiânia/GO. Porém, no estudo feito por esse mesmo autor, o $\mathrm{pH}$ das frutas liofilizadas (marolo e cagaita) foram menores do que o presente estudo. Esse acontecimento pode ter ocorrido devido a diferença de procedência dos frutos.

Tabela 2. Parâmetros físico-químicos de marolo e cagaita in natura e dos correspondentes pós liofilizados.

\begin{tabular}{lcc|cc}
\multirow{2}{*}{ Análises } & \multicolumn{2}{c}{ Marolo } & \multicolumn{2}{c}{ Cagaita } \\
\cline { 2 - 5 } & In natura & Liofilizada & In natura & Liofilizada \\
pH & $4,78^{\mathrm{a}}$ & $4,74^{\mathrm{a}}$ & $3,36^{\mathrm{b}}$ & $2,92^{\mathrm{a}}$ \\
Acidez Titulável (\% ác. & $0,78^{\mathrm{a}}$ & $1,08^{\mathrm{b}}$ & $4,19^{\mathrm{a}}$ & $8,61^{\mathrm{b}}$ \\
Cítrico/100 g de Matéria Seca) & & & & \\
Umidade (\%) & $60,80^{\mathrm{b}}$ & $1,40^{\mathrm{a}}$ & $85,40^{\mathrm{b}}$ & $6,70^{\mathrm{a}}$ \\
Sólidos Solúveis Totais $\left({ }^{\circ}\right.$ Brix) & $21,21^{\mathrm{a}}$ & $52,25^{\mathrm{b}}$ & $6,99^{\mathrm{a}}$ & $52,67^{\mathrm{b}}$ \\
\hline
\end{tabular}

*Médias seguidas por letras distintas nas linhas diferem entre si ao nivel de significancia de 5\% pelo teste de Tukey $(\mathrm{p}<0,05)$.

A legislação para frutas liofilizadas (Resolução CNNPA n 12 de 24/07/1978) estabelece o máximo 5\% de umidade para produtos liofilizados, visando minimizar a deterioração da cor, alterações de sabor e de odor induzidos pelas reações oxidativas e também restringir o desenvolvimento de microrganismo (MELONI, 2003).

Foram encontrados valores médios de umidade de 1,4 e 6,7\% para o marolo e cagaita liofilizados respectivamente. Dessa forma, o marolo atenderia a legislação vigente, enquanto que a cagaita apresentou valor superior. Provavelmente, pela presença de maior conteúdo de frutose na polpa de cagaita, o que dificulta a eficiência da liofilização devido à formação de estruturas amorfas formadas durante o congelamento que não mantiveram a estabilidade durante todo o período de liofilização, conforme relatado por Carlos et al. (2005) para a liofilização de sistemas-modelo de açúcares contendo frutose em sua constituição.

Os teores de umidade encontrados nos frutos liofilizados foram inferiores aos relatados por Martins (2006) que detectou $0,40 \%$ e $10,20 \%$ para o marolo e cagaita liofilizadas, respectivamente. Segundo Oliveira et al. (2010), a análise da umidade em alimentos é uma das medidas mais importantes, apesar de que sua determinação exata é muito difícil devido às diferentes maneiras em que a água ocorre nos alimentos (água ligada, água disponível e água livre). O teor de umidade está diretamente relacionado com a estabilidade dos alimentos, sua qualidade e composição, e pode ser afetado pelo armazenamento, embalagem e processamento (OLIVEIRA et al., 2010).

Houve um aumento na concentração dos sólidos solúveis totais (SST) no pó obtido de ambos os frutos quando comparados às polpas in natura, o que já era esperado, decorrente da eliminação de parte da água do produto no processo de secagem, conduzindo a uma concentração dos sólidos. Constatou-se que o valor de SST

Persp. online: biol. \& saúde, Campos dos Goytacazes, 23 (7), 22 - 33, 2017

seer.perspectivasonline.com.br 
do marolo in natura $\left(21,21^{\circ}\right.$ Brix) foi superior ao relatado por Bezerra (2014) (15,00 ${ }^{\circ}$ Brix). Entretanto, o conteúdo de SST do marolo em pó $\left(52,25^{\circ}\right.$ Brix) foi inferior ao resultado descrito por este mesmo autor (que foi de 68,00 ${ }^{\circ}$ Brix) para frutos procedentes de Perdões/MG. Martins (2006) observou valores inferiores de SST $\left(4,70{ }^{\circ}\right.$ Brix $)$ em cagaita in natura coletadas no estado de Goiás.

Segundo Bezerra (2014), essa variação observada no teor de SST está relacionada com características do próprio fruto. Estes teores variam com o local de produção, estádio de maturação e a variedade analisada.

A polpa de marolo in natura apresentou maior teor de glicose $(7,197 \mathrm{~g} / 100 \mathrm{~g}$ de polpa seca) e menor teor de frutose $(7,203 \mathrm{~g} / 100 \mathrm{~g}$ de polpa seca) quando comparado com a cagaita $(3,36 \mathrm{~g}$ glicose/100g de polpa seca e $8,75 \mathrm{~g}$ frutose/100g de polpa seca). O maior conteúdo de frutose detectado na polpa de cagaita aponta para a obtenção de um pó mais higroscópico. Apesar da glicose e frutose possuírem o mesmo número de hidroxilas, a última possui maior número disponível para ligar-se a água e por isso apresenta maior potencial higroscópico.

\subsection{Carotenoides}

Quanto aos conteúdos de carotenoides totais dos frutos in natura e liolilizados, apresentados na Tabela 3 , pode-se observar que houve queda significativa do teor deste componente para o marolo onde se verificou uma retenção de $66 \%$. A cagaita liofilizada também apresentou uma redução significativa $(39,25 \%)$ do conteúdo de carotenoides totais em relação ao fruto in natura, ou seja, uma retenção de $60,75 \%$ dessa classe de compostos bioativos, valor este considerado baixo levando-se em conta que o produto foi obtido por liofilização. Nascimento (2006) relatou a retenção de $74 \%$ de $\alpha$-caroteno e $77 \%$ de $\beta$-caroteno durante secagem (sob 50 e $70^{\circ} \mathrm{C}$ ) de fatias de abóboras previamente submetidas a desidratação osmótica. Segundo Mendes et al. (2013), laranjas desidratadas apresentaram perdas de conteúdo fenólico e de atividade antioxidante entre 45,1 e 37,3\% após desidratação osmótica, sendo estes valores menores aos obtidos através do uso exclusivo de secagem convencional.

Tabela 3. Teores de carotenoides das polpas de marolo e cagaita in natura e em pó (liofilizadas)

\begin{tabular}{lcccc}
\hline & \multicolumn{2}{c}{ Marolo } & \multicolumn{2}{c}{ Cagaita } \\
\cline { 2 - 5 } & In natura & Liofilizada & In natura & Liofilizada \\
\hline$\mu$ g de carotenoides/g de Matéria Seca & $15,61 \pm 1,62^{\mathrm{a}}$ & $10,32 \pm 2,63^{\mathrm{b}}$ & $82,39 \pm 0,19^{\mathrm{a}}$ & $50,04^{*} \pm 2,25^{\mathrm{b}}$ \\
\hline
\end{tabular}

*Médias seguidas por letras distintas nas linhas diferem entre si ao nivel de significancia de 5\% pelo teste de Tukey $(\mathrm{p}<0,05)$.

Embora a liofilização seja um processo de desidratação caracterizado por manter a boa qualidade sensorial e nutricional do alimento, esta técnica apresenta degradação dos carotenoides no decorrer do processo, uma vez que a estrutura celular e os complexos contidos nos alimentos podem se romper, permitindo que os carotenoides estejam susceptíveis a fatores externos, como o oxigênio, propiciando à sua destruição (ALVES et al., 2008). Cabe ressaltar ainda que a liofilização aumenta a porosidade da matriz expondo os carotenoides ao oxigênio de maneira mais efetiva (RODRIGUES-AMAYA, 1993; CARNEIRO, 2016).

Marques (2008) constatou perda de 12 e $27 \%$ de carotenoides totais para a goiaba e mamão papaya após 24 horas de liofilização em relação à polpa in natura, respectivamente. Estudando a influência de diferentes métodos de secagem do coentro, Santos et al. (2012) constataram que quanto maior a temperatura de secagem,

Persp. online: biol. \& saúde, Campos dos Goytacazes, 23 (7), 22 - 33, 2017

seer.perspectivasonline.com.br 
maior a degradação de carotenoides presentes no material, corroborando a afirmação de que a liofilização é o método de desidratação que melhor retém esse componente.

\subsection{Caracterização das frutas em pó obtidas por liofilização}

A atividade de água é um importante parâmetro na caracterização de alimentos desidratados, devido a sua influência sobre a vida útil do produto originado. Maiores valores de atividade de água indicam mais água livre disponível para as reações bioquímicas e, consequentemente, diminuição da vida útil do produto (QUEK et al., 2007). A atividade de água reportada por Martins (2006) para marolo e cagaita liofilizados $(0,54$ e 0,43 respectivamente) foram superiores aos observados no presente estudo (Tabela 4). Estas diferenças podem estar relacionadas ao tempo efetivo de liofilização de liofilização ou diferenças inerentes às variações estruturais dos frutos utilizados nos diferentes estudos.

Tabela 4. Características físicas dos pós de marolo e cagaita obtidos por liofilização.

\begin{tabular}{lcc}
\hline \multicolumn{1}{c}{ Análises } & \multicolumn{2}{c}{ Amostras } \\
\cline { 2 - 3 } & Marolo & Cagaita \\
\hline Atividade de água (Aw) & 0,25 & 0,30 \\
Solubilidade (\%) & 89,86 & 88,15 \\
Capacidade de Reidratação (\%) & 46,89 & 18,39 \\
Molhabilidade (s) & 13,56 & 52,93 \\
\hline
\end{tabular}

Para boa aceitação pelos consumidores, os produtos em pó devem ser instantâneos, ou seja, apresentar boa dispersibilidade, o que confere ao produto a característica boa instantâneabilidade. Este aspecto está associado com as características microestruturais dos pós, principalmente com a molhabilidade e solubilidade em água. Para o sucesso dos produtos em pó, inclusive para aplicações industriais, estes fatores são relevantes (BEZERRA, 2014).

A molhabilidade é um parâmetro de tempo, geralmente expresso em segundos, necessários para que todo o pó adicionado à água em repouso atinja completo desaparecimento na superfície desse líquido. Segundo Souza (2009) a molhabilidade é também conhecida como umectabilidade e pode ser designada pela susceptibilidade das partículas em serem penetradas pela água, estando associada com propriedades físicas como o tamanho e forma das partículas, a composição do alimento e características da gordura presente e a temperatura da água de reconstituição. Produtos em pó que formam grumos durante a adição e mistura com água demonstram baixa molhabilidade. Observou-se que o marolo apresentou melhor resultado de molhabilidade do que a cagaita, que durante o experimento formou vários grumos, acarretando em maior tempo para que todas as partículas ficassem submersas. Apesar da formação de grumos e mesmo com um tempo maior de molhabilidade dos pós de cagaita, os resultados foram considerados bons conforme afirmação de Lannes \& Medeiros (2003) que considera um bom parâmetro se $90 \%$ do produto mergulhar no líquido em 5 min.

Bezerra (2014) relatou variação de tempo de molhabilidade entre 14 e 39 segundos em ensaios feitos em com marolo liofilizado em pó. O presente estudo obteve valores menores (13,56 segundos), verificando-se um melhor resultado.

Persp. online: biol. \& saúde, Campos dos Goytacazes, 23 (7), 22 - 33, 2017

seer.perspectivasonline.com.br 
A solubilidade é um dos parâmetros utilizados para analisar a capacidade do pó para manter-se em mistura homogênea com a água (SOUZA, 2009). Os resultados mostram que a solubilidade dos pós é elevada em água. Dantas (2010) reportou altas solubilidades em manga e abacaxi em pó. Bezerra (2014) obteve valores superiores de solubilidade em marolo liofilizado, variando de 99,22 a 99,38\%. Os resultados obtidos de solubilidade no presente trabalho foram acima dos valores observados por Souza (2009) em pós da mistura de polpa de frutas tropicais.

Segundo Marques (2008), a capacidade de reidratação pode ser considerada uma medida das injúrias causadas pelo processo de secagem. Esse mesmo autor, em estudo da liofilização de frutas tropicais observou que a acerola e a goiaba liofilizadas apresentaram capacidades de reidratação de $42 \%$ e $39 \%$, respectivamente. O marolo liofilizado apresentou maior capacidade de reidratação do que o a cagaita liofilizada (Tabela 4).

Segundo Alexandre et al. (2007), o estudo da atividade de água pode ser feito por meio da avaliação de isortemas, que consiste em curvas que descrevem a relação entre o conteúdo de umidade dos alimentos e a atividade de água para temperatura e pressão constantes.

Figura 1. Curva de adsorção das polpas de cagaita e marolo na temperatura de $20^{\circ} \mathrm{C}$.

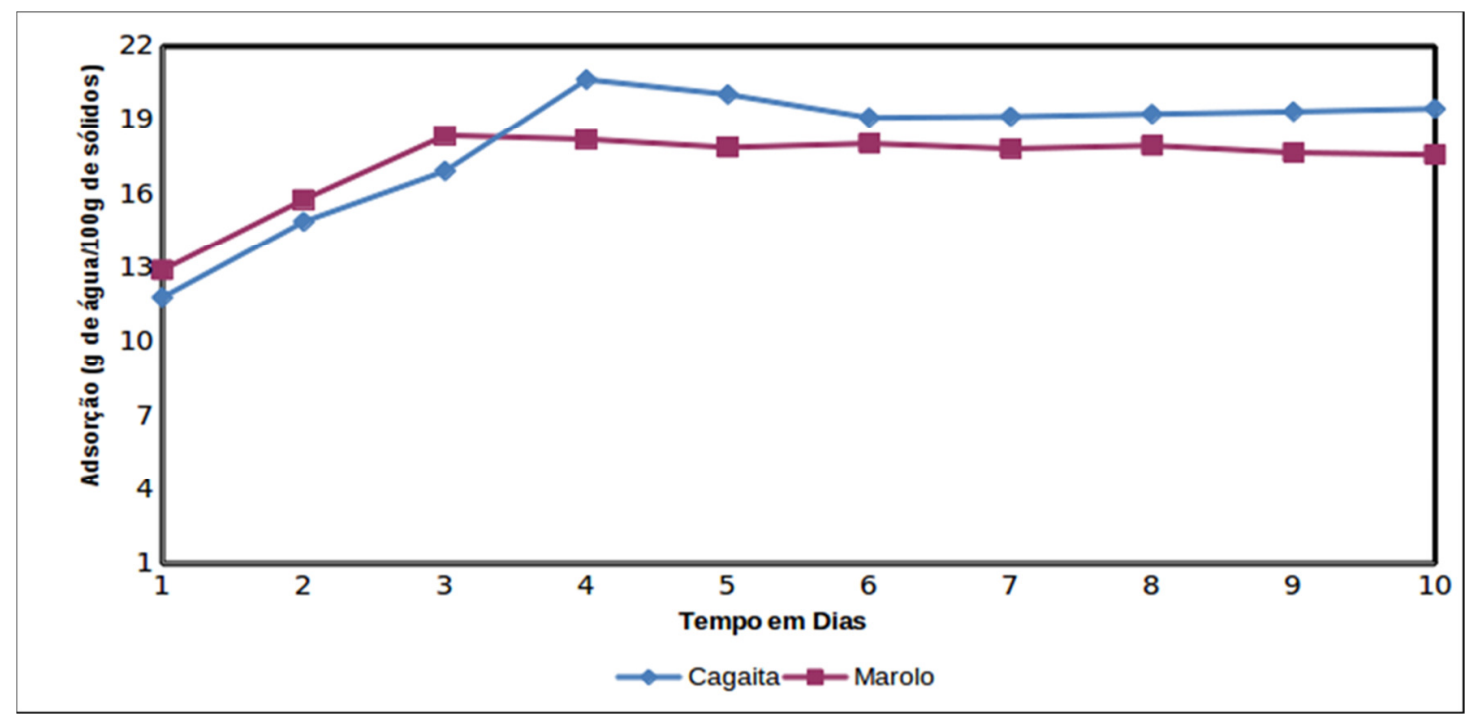

Podemos observar na Figura 1 o grau de adsorção de água dos correspondentes liofilizados de marolo e cagaita no decorrer de dez dias. Onde nota-se uma queda de adsorção pelo material liofilizado a partir do terceiro dia para o marolo e do quarto dia para a cagaita, momento em que ocorre o fenômeno de dessorção. Segundo Carlos et al. (2005), esse episódio pode ter ocorrido devido a um rearranjo estrutural dos açúcares amorfos ou parcialmente cristalizados existentes no pó.

\section{CONCLUSÃO}

O processo de liofilização das polpas in natura de marolo e de cagaita, conservou bem as características físicas e químicas. Houve retenção de carotenoides de ambos os frutos liofilizados, porém com perda significativa para o pó obtido a partir da cagaita.

Persp. online: biol. \& saúde, Campos dos Goytacazes, 23 (7), 22 - 33, 2017

seer.perspectivasonline.com.br 
A cagaita liofilizada apresentou alta atividade de água e alta higroscopicidade, provavelmente devido ao alto teor de frutose, que é mais higroscópica quando comparada a glicose e sacarose. Os liofilizados de marolo e cagaita apresentaram alta solubilidade e rápida molhabilidade.

O liofilizado de cagaita apresentou capacidade de reidratação inferior ao liofilizado de marolo. As isotermas de adsorção dos liofilizados de ambos os frutos apresentaram comportamento semelhante, típico de materiais com alto teor de açúcares.

É viável a produção de pós comestíveis de marolo e cagaita, contudo são necessários mais estudos visando minimizar a higroscopicidade dos correspondentes pós liofilizados.

\section{REFERÊNCIAS}

ALEXANDRE, H. V.; FIGUEIRÊDO, R. M. F.; QUEIROZ, A. J. M. Isotermas de adsorção de umidade de pitanga em pó. Revista de Biologia e Ciência da Terra. v.7, n.1, p. 11-20, 2007.

ALVES, C.C.O; RESENDE, J.V.; CRUVINEL, R.S.R.; PRADO, M.E.T. Estabilidade da microestrutura e do teor de carotenoides de pós obtidos da polpa de pequi (Caryocar brasiliense Camb.) iofilizada. Ciência e Tecnologia de Alimentos, Campinas, v.28, n.4, p. 830-839, 2008.

ANSARI, S.; FARAHNAKY, A.; MAJZOOBI, M. Modeling the effect of glucose syrup on the moisture sorption isotherm of figs. Food Biophysics, v.6, p.377-389, 2011.

AOAC - ASSOCIATION OF OFFICIAL ANALYTICAL CHEMISTRY. Official methods of analysis of the Association of Official Analytical Chemistry, Gaithersburg, Maryland. 3000 p. 2012.

BEZERRA, T. S. Caracterização física, química e morfológica de polpa de marolo liofilizada. Lavras: Universidade Federal de Lavras. 141f. Tese (Pós-Graduação em Ciência dos Alimentos). Lavras, MG. 2014.

BRASIL. Ministério da Saúde. Agência Nacional de Vigilância Sanitária. Resolução - CNNPA n.12, de 24/07/1978 - Dispõe sobre normas técnicas especiais. Disponível em:www.anvisa.gov.br. Acesso em 20 de setembro de 2016.

CANO-CHAUCA, M.; STRINGUETA, P. C.; RAMOS, A. M.; CAL-VIDAL, J. Effect of the carriers on the microstructure of mango powder spray drying and its functional characterization. Innovative Innovative Food Science \& Emerging Technologies, v. 6, n. 4, p. 420-428, 2005.

CARLOS, L. A.; RESENDE, J. V.; CAL-VIDAL, J. Redução da Higroscopicidade de Pós Liofilizados pela Indução da Cristalização em Soluções-Modelo de Açúcares Constituintes de Frutas. Brazilian Journal of Food Technology., v.8, n.2, p. 163-173, 2005.

CARNEIRO, B. L, A. Estabilidade química e funcional dos compostos bioativos da fruta de buriti congelada, liofilizada e atomizada. Universidade de São Paulo Escola Superior de Agricultura "Luiz de Queiroz" (USP). 111f. Dissertação (Mestrado em Ciência e Tecnologia de Alimentos). Piracicaba/SP, 2016.

DANTAS, S.C.M. Desidratação de polpas de frutas pelo método foam-mat. Universidade Federal do Rio Grande do Norte. 100f. Dissertação (Mestrado em Engenharia Química). Natal/RN, 2010.

Persp. online: biol. \& saúde, Campos dos Goytacazes, 23 (7), 22 - 33, 2017

seer.perspectivasonline.com.br 
FERREIRA, D. F. Programa SISVAR: sistema de análise de variância: versão 4,6 (Build 6,0). Lavras: DEX/UFLA., 2003.

HARDER, M. N. C.; CANNIATTI-BRAZACA, S. G.; ARTHUR, V. Avaliação quantitativa por colorímetro digital da cor do ovo de galinhas poedeiras alimentadas com urucum (Bixa orellana). Revista Portuguesa de Ciências Veterinárias, v.102, p.339-342, 2007.

ISLA, M. I.; VATTUONE, M. A.; SAMPIETRO, A.R. Hydrolysis of sucrose within isolated vacuoles from Solanum tuberosum L. tubers. Planta, v.205, n.4, p.601-605, 1998.

KING, C. J. Spray drying of food liquids and volatiles retention. In Bruin (Ed.). Preconcentration and drying of food materials. Amsterdam: Elsevier, 1988.

LANNES, S. C. S.; MEDEIROS, M. L. Processamento de achocolatado de cupuaçu por spray-dryer. Revista Brasileira de Ciências Farmacêuticas. V. 39, n.1, 2003.

MARQUES, L. G. Liofilização de frutas tropicais. Universidade Federal de São Carlos. 255 f. Tese (PósGraduação em Engenharia Química). São Carlos, SP, 2008.

MARTINS, B. A. Avaliação físico-química de frutos do cerrado in natura e processados para a elaboração de multimisturas. Universidade Católica de Goiás. 85 f. Dissertação (Pós-Graduação em Ecologia e Produção Sustentável). Goiânia, GO, 2006.

MELONI, P. L. S. Desidratação de frutas e hortaliças. Instituto Frutal, Fortaleza, 87 p, 2003.

MENDES, G. R. L., FREITAS, C.H., SCAGLIONI, P.T., SCHMIDT, C. G., FURLONG, E.B. Condições para desidratação osmótica de laranjas e as propriedades funcionais do produto. Revista Brasileira de Engenharia Agrícola e Ambiental, v.17, n.11, p.1210-1216, 2013.

NASCIMENTO, P. Avaliação da retenção de carotenoides de abóbora, mandioca e batata Doce. Universidade Estadual Paulista. 67 f. Dissertação (Mestrado em Engenharia e Ciência de Alimentos). São José do Rio Preto/SP, 2006.

OLIVEIRA, E.N.A.; SANTOS, D.C.; SOUSA, F.C.; MARTINS, J.N.; OLIVEIRA, S.P.A. Obtenção de uvaia desidratada pelo processo de liofilização. Revista Brasileira de Tecnologia Agroindustrial. v.4, n.2: p.235-242, 2010.

PINEDO, A. A.; CARNEIRO, B. L. A.; ZUNIGA, A. D. G.; ARÉVAlO, Z. D. S.; SANTANA, A. A.; PINEDO, R. A. Alterações físico-químicas e colorimétricas de geleias de araticum (Annona crassiflora). Revista Brasileira de Produtos Agroindustriais, v.15, n.4, p.397-403, 2013.

QUEK, S.Y.; CHOK, N. K.; SWEDLUND, P. The physicochemical properties of spray-dried watermelon powder. Chemical Engineering and Processing, v.46, n.5, p. 386-392. 2007.

RANGEL-MARRÓN M.; WELTI-CHANES J.; CÓRDOVA-QUIROZ A.V.; CERÓN-BRETÓN J.G.; CerónBretón R. M.; ANGUEBES-FRANSESCHI F. Estimation of moisture sorption isotherms of mango pulp freezedried. International Journal of Biology and Biomedical Engineering, v.5, p.18-23, 2011.

Persp. online: biol. \& saúde, Campos dos Goytacazes, 23 (7), 22 - 33, 2017

seer.perspectivasonline.com.br 
RATTI, C. Hot air and freeze-drying of high-value foods: a review. Journal of Food Engineering, v.49, p.311319, 2001.

ROCHA, M. S. Compostos bioativos e antioxidante (in vitro) de frutos do cerrado Piauiense. Universidade Federal do Piauí. 94 f. Dissertação (Pós-Graduação em Alimentos e Nutrição). Teresina, PI, 2011.

ROCKLAND, L. B. Satured sal solutions for static control of relative humidity between 5 and 40 C. Analitical chemistry, v. 32, n. 100, p. 1.375-1.376, 1960.

RODRIGUEZ-AMAYA, D. B. Stability of carotenoids during the storage of foods. In: CHARALAMBOUS, F. (Ed.). Shelf life studies of foods and beverages: chemical, biological, physical and nutritional aspects. Amsterdam: Elsevier Science, 1993.

RODRIGUEZ-AMAYA, D.B. A guide to carotenoid analysis in foods. Campinas: UNICAMP, 2001.

ROESLER, R.; MALTA, L. G.; CARRASCO, L. C.; HOLANDA, R. B.; SOUSA, C. A. S.; PASTORE, G. M. Atividade antioxidante de frutas do cerrado. Ciência e Tecnologia de Alimentos, v. 27, n.1, p. 53-60, 2007.

SANTOS, G.; OLIVEIRA, M.C.; MORAES, M.H.; PAGANI, A.A.C. Estudo comparativo do coentro (Coriandum sativum L.) seco obtido em diferentes métodos de secagem. Revista GEINTEC, v. 2, n.3, p.236-244, 2012.

SILVA, T. V.; RODRIGUES, J. A. S.; VIANA, A. P.; PEREIRA, S. M. F.; CARLOS, L. A.; VITORAZI, L. Determinação da escala de coloração da casca e do rendimento em suco do maracujá-amarelo em diferentes épocas de colheita. Revista Brasileira de Fruticultura, v. 30, p. 880-884, 2008.

SOUZA, J. S. Secagem de misturas de polpa de frutas tropicais em leito de jorro. Natal: Universidade Federal do Rio Grande do Norte. 178 f. Tese (Doutorado em Pesquisa e desenvolvimento de Tecnologias Regionais). Natal, RN, 2009.

VERA, R.; NAVES, R. V.; NASCIMENTO, J. L.; CHAVES, L. J.; LEANDRO, W. M.; SOUZA, E. R. B. Caracterização física de frutos do pequizeiro (Caryocar brasiliense Camb.) no estado de Goiás. Pesquisa Agropecuária Tropical, V.35, n.2, p. 71-79, 2005.

Persp. online: biol. \& saúde, Campos dos Goytacazes, 23 (7), 22 - 33, 2017

seer.perspectivasonline.com.br 